\title{
沉水植物附植生物膜藻类组成及重金属累积特征"
}

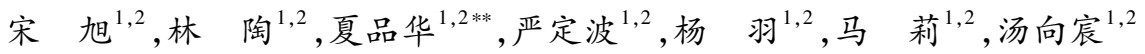 \\ (1: 贵州师范大学贵州省山地环境信息系统与生态环境保护重点实验室, 贵阳 550001) \\ ( 2 : 贵州师范大学高原湿地生态与环境研究中心, 贵阳 550001)
}

\begin{abstract}
摘 要: 沉水植物表面常富集水体中有机质、泥沙、菌胶团、藻类、微生物等形成附植生物膜,在湖泊生物地球化学循环过 程中具有重要作用. 在草海选取金鱼藻 (Ceratophyllum demersum)、微齿眼子菜 (Potamogeton maackianus) 和光叶眼子菜 (Potamogeton lucens L.) 3 种不同叶形的沉水植物, 研究附植生物膜的形貌结构、理化特征、藻类及其重金属镉 $(\mathrm{Cd}) 、$ 铅 $(\mathrm{Pb})$ 累积特征. 结果表明:3 种沉水植物附植生物膜上共鉴定出藻类 6 门 8 纲 17 目 29 科 65 属 81 种, 主要为蓝藻、绿藻 和硅藻, 不同附植生物膜藻类功能群组成不同, 圥余分析表明, 水环境因子能解释藻类功能群变化的 $88.3 \% ; 3$ 种沉水植 物附植生物膜铁 $(\mathrm{Fe})$ 、锰 $(\mathrm{Mn})$ 、总氮 $(\mathrm{TN})$ 、总磷 $(\mathrm{TP})$ 含量变化规律一致, 均为: 金鱼藻 $>$ 微齿眼子菜 $>$ 光叶眼子菜; 附植 生物膜中重金属的累积具有选择性, $\mathrm{Pb}$ 大量累积 $(11.41 \sim 41.31 \mathrm{mg} / \mathrm{kg}), \mathrm{Cd}$ 累积含量较低 $(0.59 \sim 5.76 \mathrm{mg} / \mathrm{kg})$ 且与植物相 当 $(0.44 \sim 5.56 \mathrm{mg} / \mathrm{kg})$, 附植生物膜中 $\mathrm{Pb}$ 累积含量与生物膜中隐藻门、硅藻门藻类生物量、 $\mathrm{Fe} 、 \mathrm{Mn}$ 及 $\mathrm{TN}$ 含量呈显著相 关,但 Cd 累积与生物膜各指标均无显著相关性. 附植生物膜在草型湖泊污染物归趋转化中的作用值得关注.
\end{abstract}

关键词: 沉水植物;生物膜;藻类;重金属;草海

\section{Algae composition and accumulation characteristics of heavy metals in epiphytic bioflioms of submerged macrophytes}

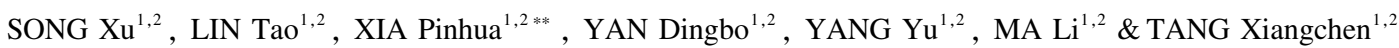 \\ (1: Key Laboratory for Information System of Mountainous Areas and Protection of Ecological Environment of Guizhou Prov- \\ ince, Guizhou Normal University, Guiyang 550001, P.R.China) \\ (2: Plateau Wetland Ecology and Environment Research Center, Guizhou Normal University, Guiyang 550001, P.R.China)
}

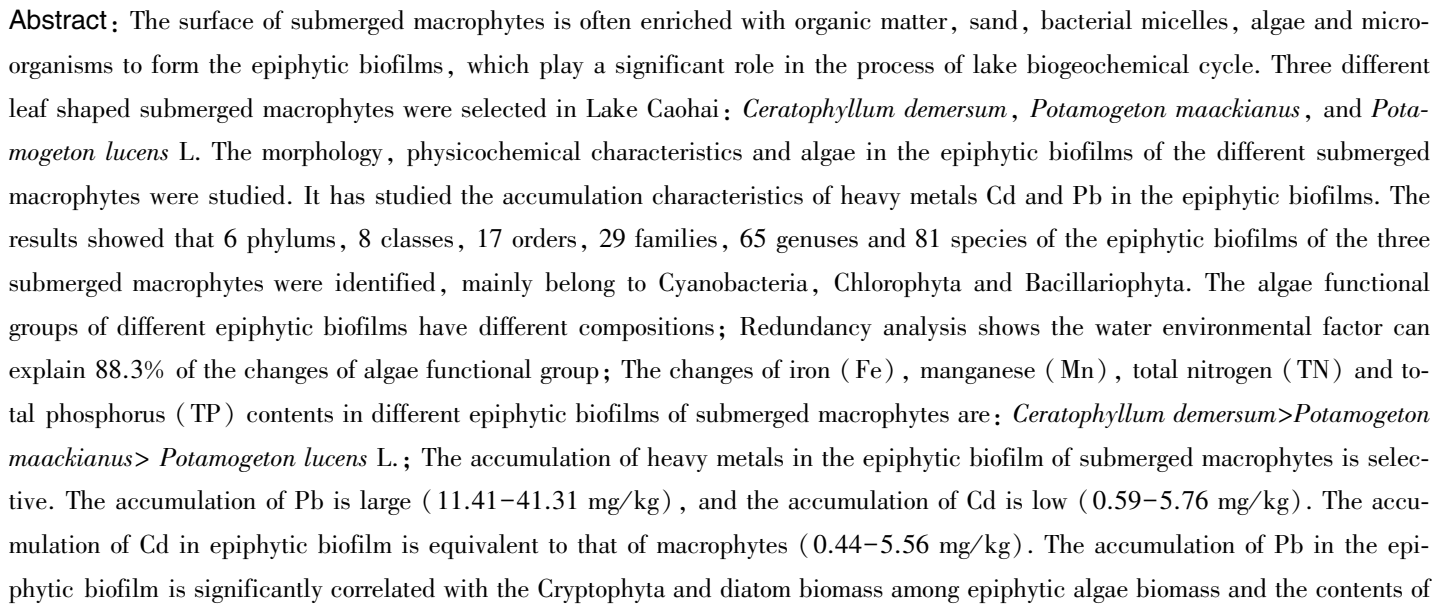

* 国家自然科学基金项目 (41867056)、贵州省重大科技专项项目 (20163022-2)、贵州省科技计划项目 (黔科合平台 人才 [2018] No.5769) 和贵州省林业科技项目(201411) 联合资助. 2019-01-03 收稿; 2019-04-02 收修改稿. 宋旭 (1993 ), 男, 硕士研究生; E-mail: 1033875263@qq.com.

** 通信作者;E-mail: pinhuayy@163.com. 
$\mathrm{Fe}, \mathrm{Mn}$ and TN in the epiphytic biofilm. However, there was no correlation between $\mathrm{Cd}$ accumulation and various indicators in biofilm. The role of epiphytic biofilm of the submerged macrophytes in the process of pollutant transformation need to pay more attention in the grass-type lakes.

Keywords: Submerged plant; biofilm; algae; heavy metal; Lake Caohai

自然水体中, 沉水植物表面常富集水体中有机质、泥沙、菌胶团、藻类、微生物等形成附植生物膜. 附植 生物膜是浅水湖泊的重要组成部分之一, 膜中附着藻类群落在水生生态系统中占据着重要的角色. 内陆水 体中的附着藻类以硅藻、绿藻和蓝藻为主 ${ }^{[1]}$. 附着藻类生物量受水体营养盐浓度的影响 ${ }^{[2]}$, 其总初级生产与 水体富营养化程度密切相关 ${ }^{[3]}$. 附着藻类对水体污染物具有很高的敏感性, 可作为污染水体监测的指示 种 $^{[4]}$; 同时藻类因于其低能耗、高吸附量、环境友好的特点, 被用于去除重金属 ${ }^{[5-6]}$; 另外, 还可以监测水体的 重金属含量 ${ }^{[7]}$.

镉 $(\mathrm{Cd})$ 和铅 $(\mathrm{Pb})$ 作为两种常见的环境重金属污染物, 不但会造成环境污染, 还能通过食物链进人人 体, 严重威胁人体健康. 生物膜对水环境中的重金属具有强烈的富集作用,在控制水环境中重金属的迁移、 毒性、生物可利用性以及最终归宿的过程中起着非常重要的作用 ${ }^{[8]}$. 多项研究表明生物膜对多种重金属 $\left(\mathrm{Cd} 、 \mathrm{~Pb}\right.$ 、锌 $(\mathrm{Zn})$ 、铜 $(\mathrm{Cu})$ 、钴 $(\mathrm{Co})$ 等) 有着较强的吸附作用 ${ }^{[9-11]}$; Beck 等 ${ }^{[12]}$ 研究发现光营养底栖生物膜会 影响渗透性沉积物中重金属 $\mathrm{Cd} 、 \mathrm{Cu}$ 、镍 $(\mathrm{Ni})$ 和 $\mathrm{Pb}$ 的迁移; 生物膜对不同重金属的吸附能力有差异, 对 $\mathrm{Cd} 、$ $\mathrm{Pb}$ 有着较强的吸附能力 ${ }^{[8-9]}$, 其影响因子众多. 在淡水环境中生物膜上的锰氧化物 (特别是生物镇氧化物) 对 $\mathrm{Cd} 、 \mathrm{~Pb}$ 等金属阳离子的吸附能力很强 ${ }^{[11,13-14]}$; 生物膜中微生物 (细菌、真菌和藻类) 对重金属也有着较强 的吸附能力 ${ }^{[15-16]}$; 而生物膜中胞外聚合物 (EPS) 同样对重金属有一定的吸附作用 ${ }^{[8]}$; 与 $\mathrm{Cd}$ 相比, Pb, Zn 和 铬 $(\mathrm{Cr})$ 的吸附主要是通过生物膜中的有机物 ${ }^{[17]}$. 而有关附植生物膜特征, 如藻类组成、铁锰氧化物含量等 与重金属 $\mathrm{Cd} 、 \mathrm{~Pb}$ 累积的关系尚不清楚.

草海是一个完整、典型的高原湿地生态系统. 由于地质背景和人类活动的影响, 草海湿地重金属 $\mathrm{Cd} 、 \mathrm{~Pb}$ 和 $\mathrm{Zn}$ 污染较重, 针对草海沉积物 ${ }^{[18]}$ 、水体 ${ }^{[19]}$ 和周边土壤 ${ }^{[20]}$ 重金属污染已有不少研究, 但是草海沉水植物 附植生物膜中 $\mathrm{Cd} 、 \mathrm{~Pb}$ 累积情况并不清楚. 鉴于此, 本文选择 3 种不同叶形的沉水植物: 光叶眼子菜、微齿眼 子菜和金鱼藻, 对其附植生物膜藻类组成、形貌、理化特征及 $\mathrm{Cd} 、 \mathrm{~Pb}$ 的累积进行研究, 揭示附植生物膜特征 对 $\mathrm{Cd} 、 \mathrm{~Pb}$ 累积的影响. 研究结果增加人们对水体自净作用的理解, 对于正确认识和利用沉水植物的生态调 控功能,改善水环境质量具有十分重要的意义.

\section{1 材料与方法}

\section{1 研究区概况}

草海位于贵州省西部威宁县县城西南面, 水域 面积约 $25 \mathrm{~km}^{2}$. 是黑颈鹤等 228 种鸟类的重要越冬 地和迁徙中转站. 水生维管束植物有 25 科 37 属 49 种, 沉水植被以眼子菜属、金鱼藻属、狐尾藻属、茨 藻属植物为主, 主要生活在水深比较深的区 域 ${ }^{[21-22]}$, 全湖共设 6 个采样点(图 1).

\section{2 草海水质}

研究期间草海水体水质参数见表 1 , 期间草海 水温 $(\mathrm{T})$ 为 $14.33^{\circ} \mathrm{C}, \mathrm{pH}$ 为 8.63 , 溶解氧 $(\mathrm{DO})$ 、化学 需氧量 $\left(\mathrm{COD}_{\mathrm{Mn}}\right)$ 和叶绿素 $\mathrm{a}(\mathrm{Chl} . \mathrm{a})$ 浓度平均值分别

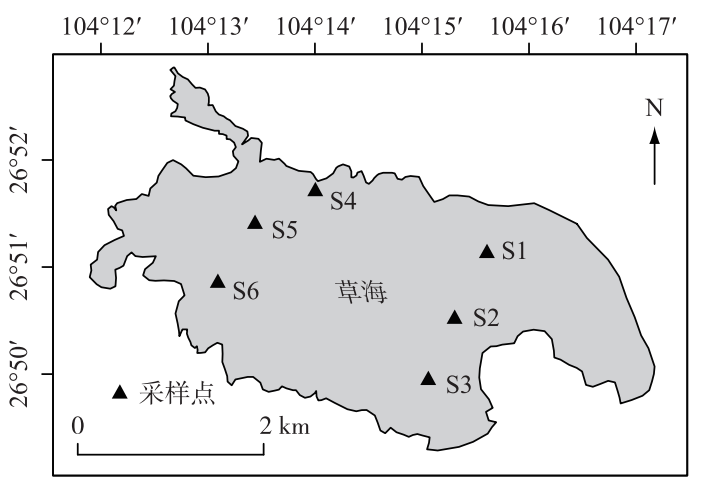

图 1 草海采样点分布

Fig. 1 Location of sampling sites in Lake Caohai 为 $9.65 \mathrm{mg} / \mathrm{L} 、 7.14 \mathrm{mg} / \mathrm{L}$ 和 $4.30 \mu \mathrm{g} / \mathrm{L}$, 水体总氮 $(\mathrm{TN})$ 、总磷 (TP) 浓度平均值分别为 $0.76 \mathrm{mg} / \mathrm{L}$ 和 $0.02 \mathrm{mg} / \mathrm{L}$, 铵态氮 $\left(\mathrm{NH}_{4}^{+}-\mathrm{N}\right)$ 浓度平均值为 $0.44 \mathrm{mg} / \mathrm{L}$. 综 合营养状态指数 $T L I(\Sigma)^{[23]}$ 为 38.88 (去除了透明度 $(\mathrm{SD})$, 因为草海充满了大量的沉水植物), 水质处于中营 养状态. 


\section{3 样品采集与处理}

采样时间为 2017 年 11 月中旬, 采样点 $\mathrm{S} 1$ 和 S2 采集植物分别为金鱼藻和微齿眼子菜, 采样点 S3 S6 采集植物为光叶眼子菜, 每个采样点植物采集 3 个平行, 按沉水植物种类将水面以下 $50 \mathrm{~cm}$ 的植株分别装人 不同的塑料瓶 (1000 ml) 中, $24 \mathrm{~h}$ 内取出, 用软毛刷仔细刷洗植株表面, 刷洗液收集并定容至 $500 \mathrm{ml}$, 取 100 $\mathrm{ml}$ 用 $5 \%$ 福尔马林溶液固定, 运用显微镜进行镜检 ${ }^{[24]}$. 将软毛刷冲洗过后的茎叶平铺在附有保鲜膜的玻璃 板上, 放在光下以直尺为对照进行拍照, 计算叶片的表面积 ${ }^{[25]}$. 冲洗后的植物在 $105^{\circ} \mathrm{C}$ 下杀青 $30 \mathrm{~min}, 90^{\circ} \mathrm{C}$ 烘干至恒重, 将烘干后的植物样磨碎后过 60 目篮保存备用 ${ }^{[26]}$; 剩余 $400 \mathrm{ml}$ 刷洗液用滤纸过滤, 置于通风处 自然风干. 将风干后的生物膜采用玛瑙研钭研磨,过 100 目微孔篮, 至全部过篮为止, 采用四分法将研磨后 的生物膜干样保存于聚乙烯塑料袋中备用 ${ }^{[27]}$; 裁取约 $4 \mathrm{~cm}^{2}$ 叶片转移到装满有 $1 \%$ 戊二醛溶液的 $30 \mathrm{ml}$ 聚乙 烯瓶中 (用 $0.1 \mathrm{~mol} / \mathrm{L}$ 稀释, $\mathrm{pH}=7.4$ ), 用于扫描电子显微镜 $(\mathrm{SEM})$ 形貌观察 ${ }^{[25]}$.

表 1 草海水质参数

Tab.1 Water quality parameters in Lake Caohai

\begin{tabular}{ccccccccc}
\hline 采样点 & $\mathrm{T} /{ }^{\circ} \mathrm{C}$ & $\begin{array}{c}\mathrm{DO} / \\
(\mathrm{mg} / \mathrm{L})\end{array}$ & $\mathrm{pH}$ & $\begin{array}{c}\mathrm{TP} / \\
(\mathrm{mg} / \mathrm{L})\end{array}$ & $\begin{array}{c}\mathrm{TN} / \\
(\mathrm{mg} / \mathrm{L})\end{array}$ & $\begin{array}{c}\mathrm{NH}_{4}^{+}-\mathrm{N} / \\
(\mathrm{mg} / \mathrm{L})\end{array}$ & $\begin{array}{c}\mathrm{COD}_{\mathrm{Mn}} / \\
(\mathrm{mg} / \mathrm{L})\end{array}$ & $\begin{array}{c}\mathrm{Chl} . \mathrm{a} / \\
(\mu \mathrm{g} / \mathrm{L})\end{array}$ \\
\hline $\mathrm{S} 1$ & $14.77 \pm 0.51$ & $11.37 \pm 0.39$ & $8.52 \pm 0.02$ & $0.03 \pm 0.003$ & $0.68 \pm 0.031$ & $0.52 \pm 0.053$ & $8.05 \pm 0.36$ & $8.59 \pm 0.95$ \\
$\mathrm{~S} 2$ & $14.60 \pm 0.17$ & $8.79 \pm 0.24$ & $8.32 \pm 0.06$ & $0.01 \pm 0.001$ & $0.95 \pm 0.086$ & $0.72 \pm 0.059$ & $7.39 \pm 0.026$ & $2.19 \pm 0.56$ \\
$\mathrm{~S} 3$ & $14.27 \pm 0.58$ & $9.53 \pm 0.26$ & $8.54 \pm 0.07$ & $0.01 \pm 0.002$ & $0.80 \pm 0.165$ & $0.36 \pm 0.034$ & $7.75 \pm 0.038$ & $5.11 \pm 0.41$ \\
$\mathrm{~S} 4$ & $14.20 \pm 0.30$ & $8.53 \pm 0.08$ & $8.48 \pm 0.05$ & $0.02 \pm 0.004$ & $0.87 \pm 0.067$ & $0.35 \pm 0.042$ & $7.35 \pm 0.14$ & $3.91 \pm 0.45$ \\
$\mathrm{~S} 5$ & $14.17 \pm 0.29$ & $9.87 \pm 0.11$ & $9.20 \pm 0.07$ & $0.02 \pm 0.002$ & $0.42 \pm 0.015$ & $0.36 \pm 0.038$ & $6.76 \pm 0.44$ & $4.64 \pm 0.60$ \\
$\mathrm{~S} 6$ & $13.97 \pm 0.15$ & $9.83 \pm 0.04$ & $8.73 \pm 0.09$ & $0.01 \pm 0.001$ & $0.86 \pm 0.05$ & $0.34 \pm 0.011$ & $5.54 \pm 0.73$ & $1.35 \pm 0.50$ \\
\hline
\end{tabular}

\section{4 数据处理及分析方法}

采用钼酸铵分光光度法 ( GB 1183-1989) 测定 TP 浓度, 采用凯氏定氮法测定 TN 浓度. 取植物和生物 膜样品各约 $0.25 \mathrm{~g}$ 待用, 生物膜中重金属全量采用浓 $\mathrm{HNO}_{3}-\mathrm{H}_{2} \mathrm{O}_{2}$ 消煮 ( $\left.\mathrm{EPA} 3050 \mathrm{~B}\right)$, 植物用 $\mathrm{HNO}_{3}-\mathrm{HClO}_{4}$ 联 合消煮 (GB/T5009.11-15-2003), 用 ZEEnit700P 原子吸收分光光度计 (150Z7P 1064) 测定植物的 $\mathrm{Cd} 、 \mathrm{~Pb}$ 含 量和附植生物膜 $\mathrm{Fe} 、 \mathrm{Mn} 、 \mathrm{Cd} 、 \mathrm{~Pb}$ 含量 ${ }^{[28]}$; 水体的富营养化程度采用综合营养指数法进行界定. 参照 《地表水 环境质量标准》( GB 3838-2002) 中的分析方法测定 $\mathrm{NH}_{4}^{+}-\mathrm{N} 、 \mathrm{TN} 、 \mathrm{COD}_{\mathrm{Mn}}$ 、TP、Chl.a 浓度. 使用 YSI 多参数水 质检测仪现场测定水温 $(\mathrm{T}) 、 \mathrm{pH}$ 和 DO 浓度; 附着藻类的物种多样性 $\left(H^{\prime}\right)$ 采用 Shannon-Wiener 多样性指 数 ${ }^{[23]}$ 进行分析:

$$
H^{\prime}=-\Sigma P_{i} \cdot \ln P_{i}
$$

式中, $P_{i}=n / N, n$ 为单个物种的数量, $N$ 为所有物种的数量. Shannon-Wiener 多样性指数评价等级: $<0.6$ 为差; $0.6 \sim 1.5$ 为一般; $1.6 \sim 2.5$ 为较好; $2.6 \sim 3.5$ 为丰富; > 3.5 为非常丰富. 本文中地图采用 ArcGIS 软件绘制, 实 验数据使用 Excel 2010 和 Origin 9.1 进行作图分析处理; 采用 SPSS 19.0 软件进行单因素方差分析 (One-way ANOVA) 检验不同植物间附植生物膜中铁 ( Fe)、镇 ( Mn)、氮 ( TN )、磷 ( TP )、 $\mathrm{Cd}$ 和 $\mathrm{Pb}$ 含量的差异显著性以 及附植生物膜组成成分与 $\mathrm{Cd} 、 \mathrm{~Pb}$ 含量的相关关系. 附着藻类功能群与环境因子的相关关系采用 Canoco5 软 件分析.

\section{2 结果与分析}

\section{1 附植生物膜形态及理化特征}

运用扫描电子显微镜 (JSM-6490) 观察了 3 种沉水植物附植生物膜结构组成 (图 2), 3 种沉水植物附植 生物膜包含大量金属氧化物、有机质、少量矿物质及丰富的胞外聚合物 (EPS), 但胞外聚合物 (EPS) 结构并 不规整. 金鱼藻附植生物膜中大量物质集中在其细小分支的交接处 (图 2a). 生物膜上观察到主要藻类有舟 形藻 (Navicula sp.)、异极藻 (Gomphonema intricalum Kutz. ) 、鼓藻 (Cosmarium sp.)、多甲藻 (Peridiniopsis sp.)、 桥弯藻 (Cymbella sp.) 等(图 2), 同时观察到一些菌丝缠绕在藻类间; 金鱼藻附植生物膜形态结构相对于微 
齿眼子菜和光叶眼子菜更加紧密.
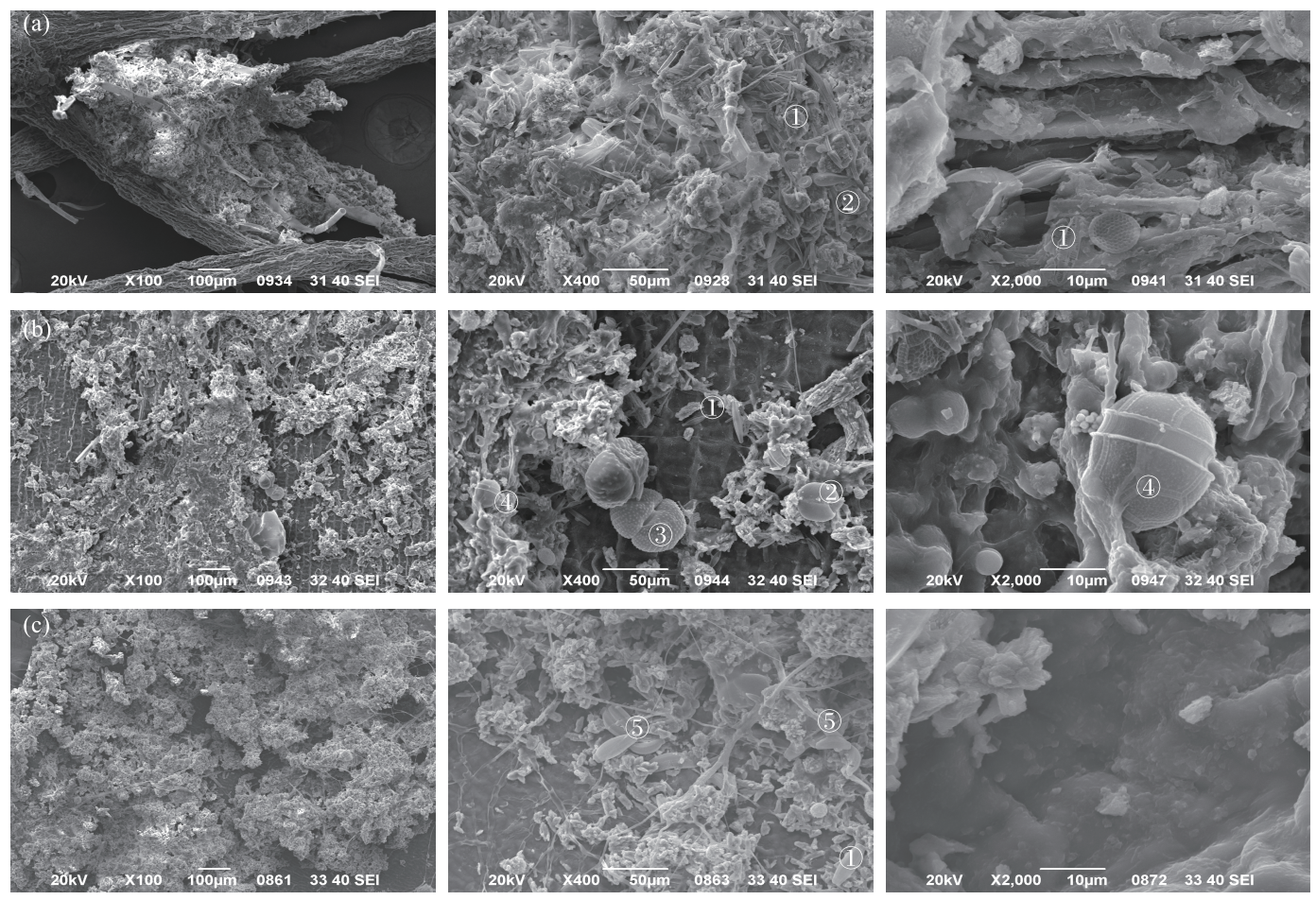

图 2 扫描电镜下金鱼藻 (a)、微齿眼子菜 (b)、光叶眼子菜 (c) 叶片表面藻类分布特征 （1)舟形藻属; 2)异极藻属; (3鼓藻属; (4)多甲藻属; (5)桥弯藻属)

Fig.2 Distribution characteristics of algae on leaf surface of Ceratophyllum demersum (a),

Potamogeton maackianus (b) and Potamogeton lucens L. (c) under scanning electron microscopy ( (1)Navicula sp.; (2)Gomphonema intricalum Kutz.; (3)Cosmarium sp.; (4)Peridiniopsis sp.; (5)Cymbella sp.)

沉水植物附植生物膜的主要化学组分包括氮、磷及铁、锰氧化物等 ${ }^{[9,29]}$. 研究区 3 种沉水植物附植生物 膜中 $\mathrm{Fe} 、 \mathrm{Mn} 、 \mathrm{TN}$ 及 $\mathrm{TP}$ 含量特征见图 3. 3 种沉水植物附植生物膜 $\mathrm{Fe} 、 \mathrm{Mn}$ 含量变化规律一致, 皆表现为金鱼 藻>微齿眼子菜>光叶眼子菜. $\mathrm{Fe}$ 含量最高为 $7825.24 \mathrm{mg} / \mathrm{kg}$, 最低为 $3098.43 \mathrm{mg} / \mathrm{kg}$; 锰含量最高为 4089.08 $\mathrm{mg} / \mathrm{kg}$, 最低为 $647.96 \mathrm{mg} / \mathrm{kg}$. TN 和 TP 含量也是金鱼藻附植生物膜中最高, 分别为 13440 和 $1110 \mathrm{mg} / \mathrm{kg}$. 光 叶眼子菜附植生物膜中 $\mathrm{TN}$ 含量最低, 为 $2380 \mathrm{mg} / \mathrm{kg}$; 微齿眼子菜附植生物膜中 $\mathrm{TP}$ 含量最低, 为 $160 \mathrm{mg} / \mathrm{kg}$; 金鱼藻附植生物膜中的 Fe 、 Mn 及 TN 、TP 含量均最高, 这与植物的叶形结构复杂程度有关. 金鱼藻簇拥在一 起, 加大了自身的吸附表面积, 其纤细且分支繁杂的叶片结构, 对水体中的悬浮物质吸附作用更强, 从而使 金鱼藻附植生物膜中的 $\mathrm{Fe} 、 \mathrm{Mn}$ 及 TN 、TP 含量更高. 生物膜中藻类也会吸收水体中的氮、磷 ${ }^{[30]}$. 金鱼藻附植 生物膜中 TN 、 TP 含量最高, 可能与其附植生物膜中藻类密度最大有关. 此外, 附植生物膜可通过磷吸收和促 进磷的沉淀、过滤水体中颗粒态的磷, 通过光合作用升高水体的 $\mathrm{pH}$, 加速 $\mathrm{Ca}-\mathrm{P}$ 和碳酸盐一磷酸盐复合体的 沉淀 ${ }^{229]}$, 使附植生物膜中磷含量升高.

\section{2 附植生物膜中藻类群落组成}

2.2.1 附植生物膜中藻类组成 通过对 3 种沉水植物附植生物膜中藻类进行鉴定, 得到藻类 6 门 8 纲 17 目 29 科 65 属 81 种,其中金鱼藻附着藻类共 6 门 8 纲 16 目 27 科 49 属 58 种, 微齿眼子菜附着藻类共 6 门 8 纲 17 目 25 科 43 属 54 种, 光叶眼子菜附着藻类共 6 门 8 纲 17 目 26 科 38 属 50 种, 25 种 (属) 藻类在 3 种沉水 植物叶片上都有检出, 在所有藻类单位面积藻类密度比例中占 $38.46 \%$. 金鱼藻附植生物膜中藻类 ShannonWiener 多样性指数最高, 为 3.23 ; 其次是微齿眼子菜, 为 3.14 ; 光叶眼子菜最低, 为 2.80 , 说明 3 种沉水植物 

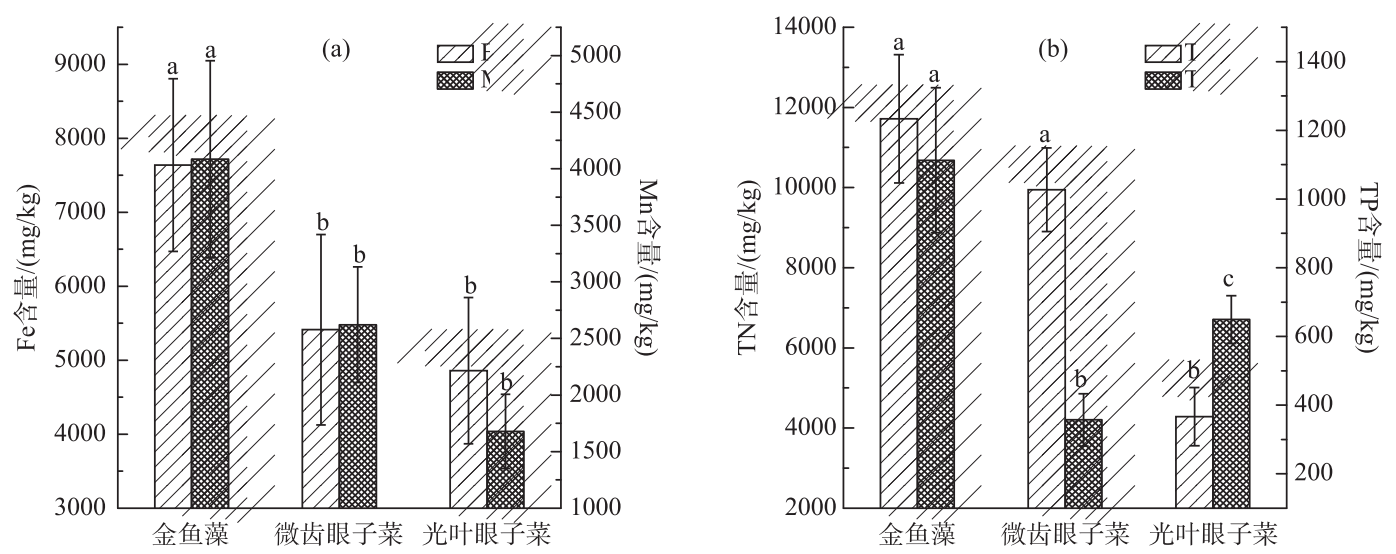

图 3 沉水植物附植生物膜中铁、锰 (a) 和氮、磷 (b) 含量

(不同小写字母表示不同附植生物膜铁、锰或氮、磷含量达到显著性差异, $P<0.05$ )

Fig.3 Iron, manganese (a) and nitrogen and phosphorus (b) contents in epiphytic bioflioms of submerged macrophytes

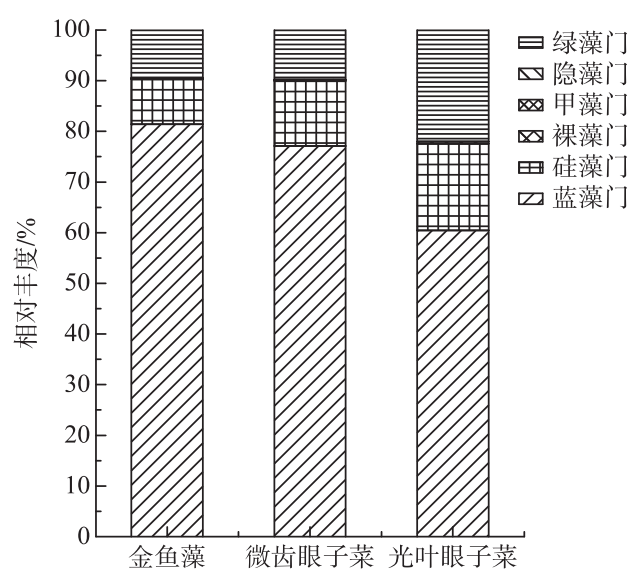

图 4 沉水植物附植生物膜中 各门藻类相对丰度

Fig.4 Relative abundance of algae class in epiphytic bioflioms of submerged macrophytes
附植生物膜中有着丰富的藻类.

金鱼藻、微齿眼子菜、光叶眼子菜单位叶片面积上 附着藻类主要包括蓝藻门、绿藻门、硅藻门、裸藻门和隐 藻门. 其中蓝藻门相对丰度最大, 其次为绿藻门和硅藻 门(图 4). 单位叶片面积上 3 种沉水植物附着藻类密度 为:金鱼藻 $\left(1.82 \times 10^{5} \mathrm{cells} / \mathrm{cm}^{2}\right)>$ 微齿眼子菜 $\left(9.93 \times 10^{4}\right.$ cells $\left./ \mathrm{cm}^{2}\right)>$ 光叶眼子菜 $\left(1.81 \times 10^{4} \mathrm{cells} / \mathrm{cm}^{2}\right)$. 单位叶片 质量上 3 种沉水植物附着藻类密度为: 金鱼藻 $(1.06 \times$ $\left.10^{8} \mathrm{cells} / \mathrm{g}\right)>$ 光叶眼子菜 $\left(6.89 \times 10^{7}\right.$ cells $\left./ \mathrm{g}\right)>$ 微齿眼子 菜 $\left(3.39 \times 10^{7} \mathrm{cells} / \mathrm{g}\right)$. 叶形精细且分支繁多的金鱼藻比 叶片宽大但复杂程度较小的光叶眼子菜和微齿眼子菜 的附着藻类密度更大.

2.2.2 附植生物膜中藻类功能群结构 参考 Reynolds 等 ${ }^{[31]}$ 和 Padisák 等 ${ }^{[32]}$ 提出的浮游植物功能群分类方法, 对鉴定出的附着藻种进行分类, 归类出 20 个功能类群, 分别为 $M 、 S 1 、 L_{0} 、 L_{M} 、 M P 、 G 、 N 、 B 、 J 、 D 、 X 1 、 F 、 A 、 P 、 W 1$ 、 $\mathrm{W} 2 、 \mathrm{Y} 、 \mathrm{X} 2 、 \mathrm{X} 3$ 和 $\mathrm{H} 1$ (表 2). 金鱼藻上归类出 18 个功能 群,无 X3 和 $\mathrm{H} 1$ 两个功能群; 微齿眼子菜上归类出 20 个

功能群; 光叶眼子菜共归类出 19 个功能群, 比金鱼藻上多了功能群 H1. 3 种沉水植物附植生物膜中单位面 积密度最大的是 $M 、 S 1 、 L_{M} 、 P 、 J 、 L_{0}$ 和 $M P$ 这 7 个功能群. 金鱼藻附着藻类单位面积密度最大的功能群为 $M$, 所占比例为 $25.62 \%$; 微齿眼子菜和光叶眼子菜附着藻类单位面积密度最大的功能群为 $\mathrm{S} 1$, 所占比例分别为 $39.23 \%$ 和 $39.14 \%$.

2.2.3 附着藻类功能群密度与环境因子的兄余分析 选取 3 种沉水植物附植生物膜中 20 个藻类功能群密度 (单位面积) 数据进行 DCA 分析检验, 结果发现最长长度梯度小于 3 , 故选择冗余分析 (RDA) 分析附着藻类 功能群密度与环境因子之间的关系. 从 7 个环境因子 $\mathrm{TN} 、 \mathrm{TP} 、 \mathrm{NH}_{4}^{+} 、 \mathrm{COD}_{\mathrm{Mn}} 、 \mathrm{DO} 、 \mathrm{Chl}$. $\mathrm{a}$ 和 $\mathrm{pH}$ 与功能群密度的 关系 (图 5) 可以看出, 轴 1 的特征值达到 0.593 ,物种一环境累计百分比为 $63.7 \%$, 说明轴 1 能解释大多数藻 类分布. 功能群 $\mathrm{H} 1 、 \mathrm{X} 3 、 \mathrm{~W} 2 、 \mathrm{~F} 、 \mathrm{X} 1$ 与环境因子 $\mathrm{TN} 、 \mathrm{NH}_{4}^{+}$呈正相关 (图 5). 而功能群 $\mathrm{X} 2 、 \mathrm{Y} 、 \mathrm{~S} 1 、 \mathrm{~L} 0 、 \mathrm{~B} 、 \mathrm{D} 、 \mathrm{~J} 、 \mathrm{G} 、$ 
$M P 、 M 、 A 、 N 、 L_{M}$ 和 $W 1$ 与环境因子 $\mathrm{COD}_{\mathrm{Mn}} 、 \mathrm{Chl} . \mathrm{a}$ 的分布呈正相关性, 即这 14 个功能群的分布受到 $\mathrm{COD}_{\mathrm{Mn}}$ 和 Chl. a 的强烈影响. 附着藻类功能群的分布受单一因子的影响, 同时也受到多种因子的共同作用, 即研究附 着藻类分布特征要考虑多因子之间的协同效应带来的影响. 3 种不同沉水植物附植藻类分布在不同象限 (图 5), 说明植物叶形复杂度对功能群的分布有明显影响, 其附着藻类的密度 (单位面积) 及种类上有明显 差异.

表 2 附着藻类功能群分组的代表性藻种及其 C-R-S 生长策略

Tab.2 Epiphytic algae functional groups and their C-R-S growth strategies

\begin{tabular}{|c|c|c|}
\hline 功能群 & 代表性藻(种) & 生长策略 \\
\hline M & 微囊藻( Microcystis sp.) & $\mathrm{S}$ \\
\hline S1 & 假鱼腥藻 (Pseudanabaena sp.)、湖丝藻 (Limnothrix sp.) & $\mathrm{R}$ \\
\hline $\mathrm{L}_{0}$ & 多甲藻 (Peridinium sp.)、色球藻 (Chroococcus sp.) 、平裂藻 (Merismopedia sp.) & $\mathrm{S}$ \\
\hline $\mathrm{L}_{\mathrm{M}}$ & 束球藻 ( Gomphosphaeria sp.) & $\mathrm{S}$ \\
\hline MP & 舟行藻 (Navicula sp.) 、桥弯藻( Cymbella sp.) 、颤藻( Oscillatoria sp.)、曲壳藻( Achnanthes sp.) & $\mathrm{CR}$ \\
\hline G & 空球藻 (Eudorina elegans) 、实球藻 (Pandorina morum) & CS \\
\hline $\mathrm{N}$ & 角星鼓藻( Staurastrum gracile) & CS \\
\hline B & 小环藻 ( Cyclotella sp.) & CR \\
\hline $\mathrm{J}$ & 栅藻 (Scenedesmus sp.) 、盘星藻 (Pediastrum sp.) 、空星藻 (Coelastrum sp.) 、四角藻( Tetraedron sp.) & $\mathrm{CR}$ \\
\hline $\mathrm{D}$ & 针杆藻( Synedra sp.)、菱板藻( Hantzschia sp.) & $\mathrm{R}$ \\
\hline $\mathrm{X} 1$ & 小球藻 (Chlorella vulgaris)、纤维藻( Ankistrodesmus sp.)、弓形( Schroederia sp. ) & $\mathrm{C}$ \\
\hline $\mathrm{F}$ & 卵囊藻( Oocystis sp.)、蹄形藻 (Kirchnecriella sp.) 、微芒藻( Micractinium pusillum) & CS \\
\hline A & 普通等片藻 (Diatoma vulgare) & $\mathrm{R}$ \\
\hline $\mathrm{P}$ & $\begin{array}{l}\text { 角星鼓藻 (Staurastrum sp.) 、脆杆藻 (Fragilaria sp.)、新月藻 (Closterium sp.)、颗粒直链藻 } \\
\text { (Aulacoseria granulate) }\end{array}$ & $\mathrm{R}$ \\
\hline W1 & 裸藻 (Euglena $\mathrm{sp})$. & $\mathrm{R} / \mathrm{CS}$ \\
\hline W2 & 囊裸藻 ( Trachelomononas sp.) & $\mathrm{R} / \mathrm{CS}$ \\
\hline $\mathrm{Y}$ & 隐藻( Cryptomonas sp.) & CRS \\
\hline $\mathrm{X} 2$ & 衣藻( Chlamydomonas sp.) & $\mathrm{C}$ \\
\hline $\mathrm{X} 3$ & 普通肋缝藻 ( Frustulia vulgaris) & $\mathrm{C}$ \\
\hline H1 & 水华束丝藻 (Aphanizomenon flosaquae) & CS \\
\hline
\end{tabular}

\section{3 沉水植物及附植生物膜对重金属 $\mathrm{Cd} 、 \mathrm{~Pb}$ 的累积特征}

沉水植物及其生物膜中的 $\mathrm{Cd}$ 含量分别在 $0.44 \sim 5.56 \mathrm{mg} / \mathrm{kg}$ 和 $0.59 \sim 5.76 \mathrm{mg} / \mathrm{kg}$ 之间 (图 6), 植物与生 物膜中含量差异不大 (光叶眼子菜除外); 生物膜中 $\mathrm{Pb}$ 含量 $(11.41 \sim 41.31 \mathrm{mg} / \mathrm{kg})$ 远高于植物体中 ( $0.57 \sim$ $9.53 \mathrm{mg} / \mathrm{kg})$, 差异极显著 $(P<0.005) . \mathrm{Cd} 、 \mathrm{~Pb}$ 含量在光叶眼子菜生物膜中均最低, 但 $\mathrm{Cd}$ 含量在微齿眼子菜 生物膜中最高, $\mathrm{Pb}$ 含量在金鱼藻生物膜中最高. 3 种附植生物膜中 $\mathrm{Pb}$ 含量都高于 $\mathrm{Cd}$ 含量, 表明生物膜对 $\mathrm{Pb}$ 的富集能力高于 $\mathrm{Cd}$. 附植生物膜中 $\mathrm{Cd}$ 含量均高于贵州表生沉积物背景值 $(0.31 \mathrm{mg} / \mathrm{kg})$; 金鱼藻及微齿 眼子菜生物膜中 $\mathrm{Pb}$ 含量高于贵州表生沉积物背景值 $(29.39 \mathrm{mg} / \mathrm{kg})^{[33]}$.

根据 Pearson 相关性分析, 可知附植生物膜中总的藻类生物量及各门类水平藻类生物量 (单位面积) 、理化 组成 ( Fe、Mn、TN 和 TP 含量) 与重金属 $\mathrm{Cd} 、 \mathrm{~Pb}$ 累积的相关关系 (表 3), 得到 $\mathrm{Pb}$ 累积含量与附植生物膜中硅藻 门藻类生物呈极显著相关 $(P<0.001)$, 与隐藻门藻类生物量、 $\mathrm{Fe}$ 和 $\mathrm{Mn}$ 含量、TN 含量呈显著相关 $(P<0.05)$.

\section{3 讨论}

\section{1 附植生物膜藻类群落差异及影响因素}

3 种不同叶形沉水植物附着藻类功能群组成和数量不同. 金鱼藻附着藻类的密度及藻类多样性指数均 高于微齿眼子菜与光叶眼子菜, 这与 Laugaste 等 ${ }^{[34]}$ 的研究相似. 附着藻类的生物量也不尽相同, 不同的植物 类型影响着附着藻类的生物量 ${ }^{[35]}$. 不同附着藻类群落组成和生物量的差异与环境因子和植物本身有关. 


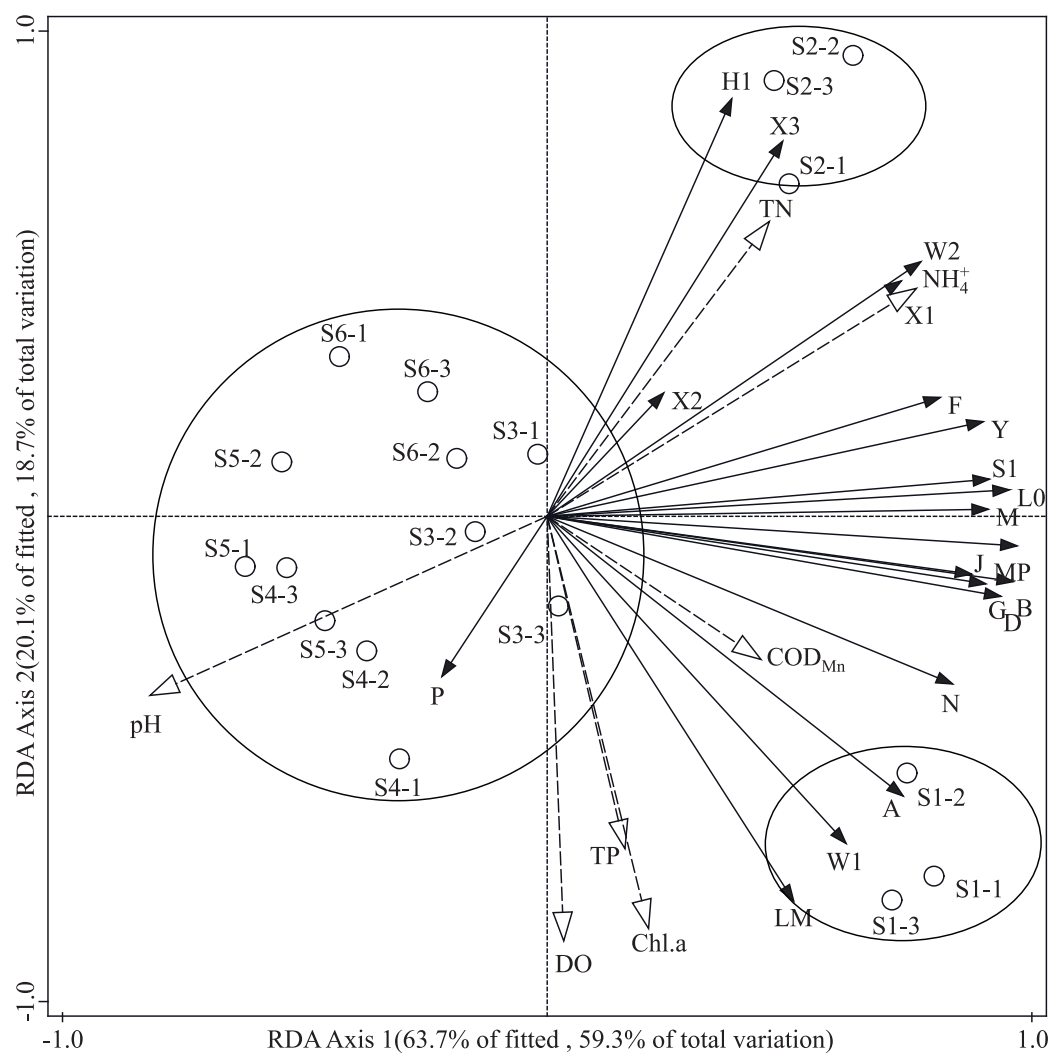

图 5 附着藻类功能群圥余分析

Fig.5 Redundancy analysis of epiphytic algae functional groups related to environmental factors
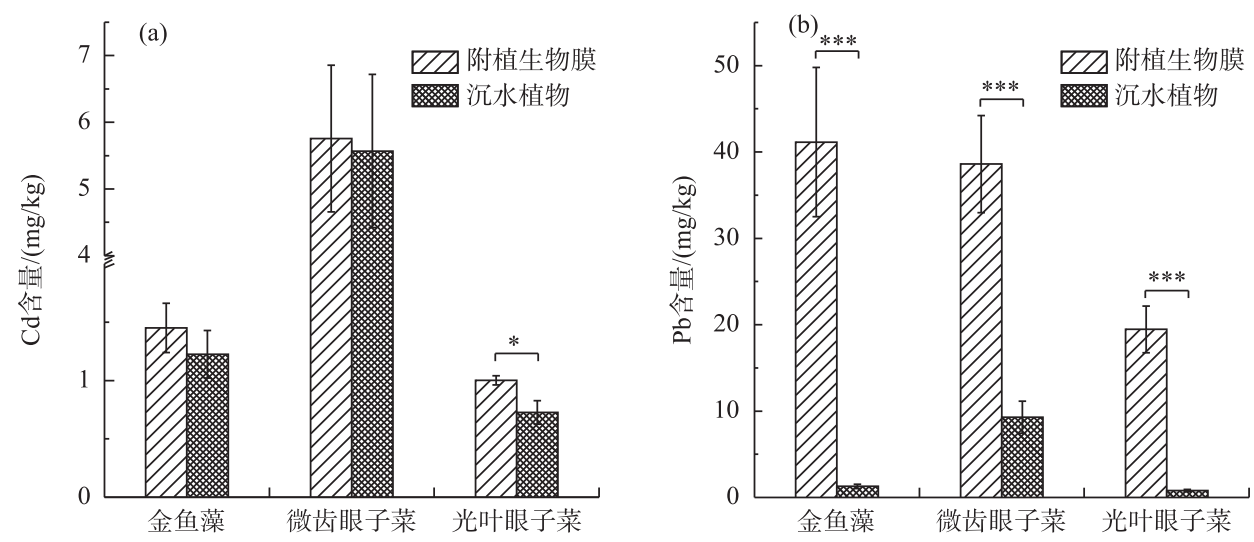

图 6 沉水植物与附植生物膜中重金属 $\mathrm{Cd}(\mathrm{a})$ 和 $\mathrm{Pb}(\mathrm{b})$ 含量

$(*$ 表示 $P<0.05, * *$ 表示 $P<0.01, * * *$ 表示 $P<0.005)$

Fig.6 Contents of heavy metals $\mathrm{Cd}$ ( a) and $\mathrm{Pb}(\mathrm{b})$ in submerged macrophytes and epiphytic biofilm

首先, 水体理化因子对附植生物膜藻类群落具有重要影响. 草海沉水植物附植生物膜中的藻类分布与 水体物理化学因子有显著的相关关系, 说明附着藻类生长状况易受水体环境中物理化学因素的影响 ${ }^{[7]}$, 附 着藻类的组成结构受水体中光照、营养盐等因素的影响. 已有研究表明, 附着藻类的总初级生产与水体富营 
表 3 沉水植物附植生物膜组成成分与重金属 $\mathrm{Cd} 、 \mathrm{~Pb}$ 含量的相关关系

Tab.3 The correlation between heavy metal $\mathrm{Cd}$ and $\mathrm{Pb}$ accumulation and composition of epiphytic bioflioms of submerged macrophytes

\begin{tabular}{ccccccccccccc}
\hline & 蓝藻门 & 硅藻门 & 裸藻门 & 甲藻门 & 绿藻门 & 隐藻门 & 藻类生物量 & Fe & $\mathrm{Mn}$ & $\mathrm{TN}$ & $\mathrm{TP}$ \\
\hline $\mathrm{Cd}$ & 0.25 & 0.53 & 0.12 & 0.02 & -0.16 & 0.77 & 0.24 & 0.20 & 0.31 & 0.49 & -0.24 \\
$\mathrm{~Pb}$ & 0.67 & $0.93^{* *}$ & 0.58 & 0.63 & 0.004 & $0.89^{*}$ & 0.66 & $0.87^{*}$ & $0.85^{*}$ & $0.93^{* *}$ & 0.40 \\
\hline
\end{tabular}

*表示显著相关, $P<0.05$; $* *$ 表示极显著相关, $P<0.001$.

养化程度呈正相关关系 ${ }^{[3]}$, 随着营养盐浓度的升高, 附着藻类生物量会显著增加 ${ }^{[36]}$; 而附着藻类由于固着生 活不能主动或者被动改变深度, 其生长及群落组成会受光的影响 ${ }^{[7]}$; 在通常情况下, 淡水水体 $\mathrm{pH}$ 偏碱性,绝 大多数无机碳以 $\mathrm{HCO}_{3}$ 形式存在, 并能被藻类吸收利用, 水体 $\mathrm{HCO}_{3}$ - 缺乏势必会对附着藻类的生长产生影 响 ${ }^{[37]}$; 水动力扰动也是影响附着藻类群落组成的一个因素, 不仅影响附着藻类群落组成, 还通过扰动沉积物 再悬浮来影响水体营养盐浓度及水体光的传播, 进而影响藻类的发展 ${ }^{[38]}$. 反之, 附着藻类也会对沉水植物 光合作用产生影响,进而影响沉水植物的生长 ${ }^{[39]}$.

其次,植物本身也会影响藻类群落结构. 水生植物的形态为附着藻类提供了重要的栖息地,而植物结构 固有的空间复杂性创造了多样的结构, 使得附着藻类能够最大限度地附着和获得阳光 ${ }^{[40-41]}$. 在同一地点, 不 同沉水植物在相似的环境条件下, 其附着植物群落组成存在显著差异 ${ }^{[42]}$. 这可能归因于藻类附着对特定底 物的亲和力, 诸如宿主植物表面积和表面的微纹理不同 ${ }^{[43]}$. 植物的形状和排列、比表面积或生物量都会导 致其附着藻类的生物量不同. 也就是说, 大型植物上的附着藻类生物量受植物结构的复杂性和排列性的影 响,因此复杂的结构不仅比简单的结构提供更大的比表面积,而且提供了最大限度获得光的附着点. 金鱼藻 叶形和排列方式不同于微齿眼子菜与光叶眼子菜, 它在自然水体中成团簇拥在一起生长, 拥有更大的附着 表面区域而可以产生更多的附着藻类 ${ }^{[35]}$. 另外, 像金鱼藻这种具有复杂结构的植物, 其表面较高的附着生 物量也可能是由于其牧食压力的降低, 因为鱼类在更复杂的生境中受食效率较低 ${ }^{[42]}$, 这也是金鱼藻附植生 物膜中藻类密度及藻类多样性指数最高的原因之一.

\section{2 附植生物膜 $\mathrm{Cd} 、 \mathrm{~Pb}$ 累积差异成因}

附植生物膜对水体重金属 $\mathrm{Cd} 、 \mathrm{~Pb}$ 具有较强累积作用,附植生物膜对 $\mathrm{Pb}$ 的累积远高于 $\mathrm{Cd}$,与以往生物 膜对重金属的吸附能力为 $\mathrm{Pb}>\mathrm{Cu}>\mathrm{Cd}$ 的结论一致 ${ }^{[10]}$. 一方面可能与附植生物膜特征, 如藻类、胞外聚合物、 铁镇氧化物等有关. 生物膜中的藻类会吸附和富集水环境中的重金属 ${ }^{[16]}$, 其方式包括: 络合、离子交换、氧 化还原、胞外聚合物、胞内聚合物和液泡区室化. 生物膜中有机成分 EPS 也会吸附重金属 $\mathrm{Cd} 、 \mathrm{~Pb}$, 且对 $\mathrm{Pb}$ 的 结合能力比 $\mathrm{Cd}$ 强 ${ }^{[44]}$. 生物膜中的无机物即铁、镇氧化物对重金属的吸附起着主要作用 ${ }^{[8]}$. 生物膜中微生物 对不同重金属的吸附有选择性且与金属离子的电负性、离子势、离子半径和氧化还原电势等性质有关; 此外 微生物能通过多种途径将重金属吸附在其细胞表面, 而细胞壁则是金属离子的主要积累场所 ${ }^{[15]}$. 另一方 面, 与 $\mathrm{Cd} 、 \mathrm{~Pb}$ 竞争吸附有关, 不同离子间存在竞争吸附, 比如在多相体系中, 生物膜对 $\mathrm{Cd} 、 \mathrm{~Pb}$ 和 $\mathrm{Cu}$ 总体的吸 附量有所下降, 3 种金属在生物膜上的吸附分配比发生了变化, $\mathrm{Pb}$ 所占比例升高, $\mathrm{Cd}$ 和 $\mathrm{Cu}$ 所占比例降 低 ${ }^{[11]}$; $\mathrm{Cd}^{2+}$ 的存在会影响 $\mathrm{Pb}^{2+}$ 的吸附 ${ }^{[10]}$. 此外,水体环境也会对生物膜吸附重金属产生影响. 田超等 ${ }^{[45]}$ 的 研究发现生物膜对 $\mathrm{Pb}^{2+}$ 的吸附选择性明显比 $\mathrm{Zn}^{2+}$ 强, 在 $\mathrm{pH}$ 为 $6 \sim 7$ 、温度为 $25 \sim 30^{\circ} \mathrm{C}$ 的条件下, 生物膜对 $\mathrm{Pb}$ 有较强的吸附能力. 从本研究中附植生物膜组成成分与重金属 $\mathrm{Cd} 、 \mathrm{~Pb}$ 累积的相关性分析可知, $\mathrm{Pb}$ 累积含量 与生物膜中隐藻门、硅藻门藻类生物量 $(P<0.01)$ 及 $\mathrm{Fe} 、 \mathrm{Mn} 、 \mathrm{TN}$ 含量显著相关 (表 3) $(P<0.05)$, 与总的藻类 生物量无相关关系; 说明附植生物膜对于 $\mathrm{Pb}$ 的累积作用与附着藻类中的隐藻门、硅藻门的藻类生物量密切 相关; 而生物膜中的理化物质如 $\mathrm{Fe} 、 \mathrm{Mn}$ 和 $\mathrm{TN}$ 含量都会影响对 $\mathrm{Pb}$ 的累积. 而 $\mathrm{Cd}$ 含量与生物膜所测指标均 无关系, 表明附植生物膜对 $\mathrm{Cd}$ 的累积可能与外部环境因子有关. 可见, 附植生物膜中重金属的累积与重金 属自身的属性、生物膜特征及环境条件密切相关.

\section{4 结论}

1) 沉水植物附植生物膜的主要化学组分是铁、锰氧化物, 附植生物膜作为水体氮、磷的主要库存者, 含 
有大量氮、磷物质, 叶形精细且分支繁多的金鱼藻附植生物膜中铁、锰氧化物含量及氮、磷含量高于微齿眼 子菜与光叶眼子菜.

2) 金鱼藻、微齿眼子菜和光叶眼子菜附植生物膜中共鉴定出藻类 6 门 8 纲 17 目 29 科 65 属 81 种, 以蓝 藻门、绿藻门和硅藻门为主, 不同叶形沉水植物附着藻类组成和密度不同, 叶形结构较复杂的金鱼藻附着藻 类密度最大,受水环境因子和植物的双重影响.

3) 附植生物膜对水体中 $\mathrm{Cd} 、 \mathrm{~Pb}$ 的累积具有选择性, $\mathrm{Pb}$ 的累积显著高于 $\mathrm{Cd}$, 这与生物膜特性有关, 如理 化特性 (生物膜铁镇氧化物含量)、生物特性 (藻类种类及群落结构) 等.

\section{5 参考文献}

[ 1 ] Kalff J ed. Limnology: Inland water ecosystem. Beijing: Higher Education Press, 2011.

[ 2 ] Quinlan EL, Phlips EJ, Donnelly KA et al. Primary producers and nutrient loading in Silver Springs, FL, USA. Aquatic Botany, 2008, 88(3): 0-255.

[ 3 ] Ma MY, Cui LJ, Zhang MY et al. Primary production of periphyton and their relationship to water quality in Baiyangdian Lake, China. Acta Ecologica Sinica, 2018. [马牧源, 崔丽娟, 张曼胤等. 白洋淀附着藻类的初级生产力及其与水质 的关系, 生态学报, 2018.]

[ 4 ] Yuan XF, Shi HH, Wang XR. Temporal and spatial distributions of periphytic algae in Taihu Lake. Journal of Agro-Environment Science, 2006, 25(4) : 1035-1040. [袁信芳, 施华宏, 王晓蓉. 太湖着生藻类的时空分布特征. 农业环境科 学学报, 2006, 25(4): 1035-1040.]

[ 5 ] Pandey LK, Kumar D, Yadav A et al. Morphological abnormalities in periphytic diatoms as a tool for biomonitoring of heavy metal pollution in a river. Ecological Indicators, 2014, 36: 272-279.

[ 6 ] Jacinto MLJAJ, David CPC, Perez TR et al. Comparative efficiency of algal biofilters in the removal of chromium and copper from wastewater. Ecological Engineering, 2009, 35(5): 856-860.

[ 7 ] Ji HT, Xie D, Zhou HJ et al. Advances in ecological research on epiphytic community of submerged macrophytes. J Lake Sci, 2013, 25(2) : 163-170. DOI: 10.18307/2013.0201. [ 纪海婷, 谢冬, 周恒杰等. 沉水植物附植生物群落生态学 研究进展. 湖泊科学, 2013, 25(2): 163-170.]

[ 8 ] Dong DM, Li Y, Hua XY et al. Relationship between chemical composition of surface coatings and waters in natural waters. Chemical Journal of Chinese Universities, 2002, 23(8): 1507-1509. [董德明, 李鱼, 花修艺等. 自然水体中生物 膜的主要化学组分与水体中相关化学物质的关系. 高等学校化学学报, 2002, 23(8): 1507-1509.]

[ 9 ] Kang CL, Guo J, Guo P et al. Adsorption behavior of $\mathrm{Pb}^{2+}$ by organic components of natural biofilms in natural water and the influencing factors. Chemical Journal of Chinese Universities, 2005, 26(11): 2043-2045. [康春莉, 郭晶, 郭平等. 自然水体生物膜有机组分对 $\mathrm{Pb}^{2+}$ 的吸附特性及其影响因素. 高等学校化学学报, 2005, 26(11): 2043-2045.]

[10] Zheng N, Hua XY, Dong DM et al. Competitive adsorption of metal cations onto natural surface coatings. Journal of Jilin University: Science Edition, 2005, 43(3): 388-393. [郑娜, 花修艺, 董德明等. 重金属在自然水体生物膜上的竞争 吸附. 吉林大学学报: 理学版, 2005, 43(3): 388-393.]

[11] Dong D. Adsorption of $\mathrm{Pb}$ and $\mathrm{Cd}$ onto metal oxides and organic material in natural surface coatings as determined by selective extractions: new evidence for the importance of Mn and Fe oxides. Water Research, 2000, 34(2) : 427-436.

[12] Beck AJ, Beer JDD. The influence of phototrophic benthic biofilms on $\mathrm{Cd}, \mathrm{Cu}, \mathrm{Ni}$, and $\mathrm{Pb}$ transport in permeable sediments. Biogeochemistry, 2011, 102(1/2/3) : 167-181.

[13] Dong D, Liu L, Hua X et al. Comparison of lead, cadmium, copper and cobalt adsorption onto metal oxides and organic materials in natural surface coatings. Microchemical Journal, 2007, 85(2) : 270-275.

[14] Haack EA, Warren LA. Biofilm hydrous manganese oxyhydroxides and metal dynamics in acid rock drainage. Environmental Science \& Technology, 2003, 37 (18): 4138-4147.

[15] Liu P, Zeng GM, Huang JH et al. Research progress of biosorption in treatment of waste water containing heavy metals. Industrial Water and Wastewater, 2004, 35(5): 1-5. [ 刘萍, 曾光明, 黄瑾辉等. 生物吸附在含重金属废水处理中的研 究进展. 工业用水与废水, $2004,35(5): 1-5$. $]$

[16] Zheng MM, Shao LZ, Zhou SQ et al. Mechanism and application of algae enrichment of heavy metals in water. Environmental Science and Technology, 2017, 30(6): 66-70. [郑蒙蒙, 邵鲁泽, 周思齐等. 藻类富集水体重金属的机理及应 
用. 环境科技, 2017, 30(6): 66-70.]

[17] Drahota P, Škaloud P, Nováková B et al. Comparison of $\mathrm{Pb}, \mathrm{Zn}, \mathrm{Cd}, \mathrm{As}, \mathrm{Cr}$, Mo and Sb adsorption onto natural surface coatings in a stream draining natural as geochemical anomaly. Bulletin of Environmental Contamination \& Toxicology, 2014, 93(3): 311-315.

[18] Zhang ZL, Tan H, He JL et al. Distribution characteristics and source identification of heavy metals in surface sediments of Caohai Lake in Guizhou. Ecology and Environmental Sciences, 2018, (12): 2314-2320. [张转玲, 谭红, 何锦林等. 贵 州草海表层沉积物重金属污染特征及来源分析. 生态环境学报, 2018, (12) : 2314-2320.]

[19] Zhu YZ, He TR, Gao Z et al. Distribution of heavy metals in sediments and its impact on zoobenthos community of Lake Caohai in Guizhou. China Environmental Science, 2016, 36(6): 1859-1866. [ 朱玉珍, 何天容, 高钊. 贵州草海沉积物 重金属分布及其对底栖动物群落的影响. 中国环境科学, 2016, 36(6) : 1859-1866.]

[20] Zhang JZ, Lin SX, Zhang QH et al. Characteristics of heavy metal pollution in crops and soil around Caohai Wetland in Guizhou Province. Research of Soil and Water Conservation, 2014, 21(3) : 273-278. [ 张家春, 林绍霞, 张清海等. 贵州 草海湿地周边耕地土壤与农作物重金属污染特征. 水土保持研究, 2014, 21(3):273-278.]

[21] Tang JG, Li WJ, Zhou CY. Study on aquatic plant diversity changes in Caohai plateau wetland. Guihaia, 2014, ( 5 ): 601-607. [ 唐金刚, 李苇洁, 周传艳. 高原湿地草海水生植物多样性变化研究. 广西植物, 2014, (5) : 601-607.]

[22] Xiang G, Zhou H, Wang CL. Flora studies on aquatic vascular plants in Caohai Lake. Journal of Guizhou Normal University: Natural Sciences, 2009, (3) : 9-14. [ 向刚, 周红, 王承录. 贵州草海水生维管植物区系地理研究. 贵州师范大学 学报: 自然科学版, 2009, (3) : 9-14.]

[23] Xia YF, Hu XD, Xu JX et al. Seasonal succession of phytoplankton functional group and assessment of water quality in Lake Taihu. J Lake Sci, 2019, 31(1) : 134-146. DOI: 10.18307/2019.0113. [夏荣霏, 胡晓东, 徐季雄等. 太湖浮游 植物功能群季节演替特征及水质评价. 湖泊科学, 2019, 31(1) : 134-146. ]

[24] Hu HJ, Wei YX eds. Chinese freshwater algae—system, classification and ecology. Beijing: Science Press, 2006. [ 胡鸿 钧, 魏印心. 中国淡水藻类——系统、分类及生态, 2006.]

[25] Liu KH, Zhang SH, Lu XY et al. The characteristics of epiphytic microbes of three submerged macrophytes in Lake Huashen. J Lake Sci, 2015, 27 (1) : 103-112. DOI: 10.18307/2015.0113. [刘凯辉, 张松贺, 吕小央等. 南京花神湖 3 种 沉水植物表面附着微生物群落特征. 湖泊科学, 2015, 27(1): 103-112.]

[26] Qiao YL, Li MH, Xie PJ et al. A study on the absorption of cadmium and zinc in the water sediments with submerged plants. Journal of Zhejiang University: Science Edition, 2016, 43(5): 601-609. [乔云蕾, 李铭红, 谢佩君等. 沉水植 物对受重金属镉、锌污染的水体底泥的修复效果. 浙江大学学报: 理学版, 2016, 43(5): 601-609.]

[27] Li ZX, Yuan LH, Lei HY et al. Study on adsorption and migration regularity of heavy metals by biofilm in Tidal River. Journal of Anhui Agricultural Sciences, 2011, (34) : 21217-21220. [ 李召旭, 袁丽华, 雷恒毅等. 感潮河道生物膜吸附 重金属性能及迁移规律研究. 安徽农业科学, 2011, (34) : 21217-21220.]

[28] Lei M, Yue QL, Chen TB et al. Heavy metal concentrations in soils and plants around Shizhuyuan mining area of Hu'nan Province. Acta Ecologica Sinica, 2004, 25(5): 1146-1151. [雷梅, 岳庆玲, 陈同斌等. 湖南柿竹园矿区土壤重金属 含量及植物吸收特征. 生态学报, 2004, 25(5): 1146-1151.]

[29] Dodds WK. The role of periphyton in phosphorus retention in shallow fresh water aquatic systems. Journal of Phycology, 2010, 39(5): 840-849.

[30] Song YZ, Feng Y, Wang JQ et al. Effects of nitrogen and phosphorus availability on epiphytic algae attaching to the macrophyte Vallisneria natans. Acta Scientiae Circumstantiae, 2018, 38(12): 4721-4727. [ 宋玉芝, 丰叶, 王锦旗等. 水体及 沉积物氮磷水平对附植藻类的影响. 环境科学学报, 2018, 38(12) : 4721-4727.]

[31] Reynolds CS, Huszar V, Kruk C et al. Towards a functional classification of the freshwater phytoplankton. Journal of Plankton Research, 2002, 24(5) : 417-428.

[32] Padisák J, Crossetti LO, Naselli-Flores L. Use and misuse in the application of the phytoplankton functional classification: a critical review with updates. Hydrobiologia, 2009, 621(1): 1-19.

[33] Liu XB, Liu XL, Li X et al. Distribution and pollution assessment of heavy metals in surface sediments from Cao hai Lake, Guizhou. Journal of Safety and Environment, 2016, 16(1) : 325-332. [刘宪斌, 刘新蕾, 李厦等. 贵州草海表层沉积物 重金属分布特征及污染评价. 安全与环境学报, 2016, 16(1):325-332.]

[34] Laugaste R, Reunanen M. The composition and density of epiphyton on some macrophyte species in the partly meromictic 
Lake Verevi. Hydrobiologia, 2005, 547 (1) : 137-150.

[35] Pettit NE, Ward DP, Adame MF et al. Influence of aquatic plant architecture on epiphyte biomass on a tropical river floodplain. Aquatic Botany, 2016, 129: 35-43.

[36] Quinlan EL, Phlips EJ, Donnelly KA et al. Primary producers and nutrient loading in Silver Springs, FL, USA. Aquatic Botany, 2008, 88(3): 247-255.

[37] Yue GF, Wang JX, Zhu MY et al. Progress of inorganic carbon acqusition by alage ( I ) : Origen and methods of the studies. Marine Sciences, 2003, 27 (5) : 15-18. [岳国峰, 王金霞, 朱明远等. 藻类无机碳营养的研究进展 ( I ) 一一研 究起源及研究方法. 海洋科学, 2003, 27(5) : 15-18.]

[38] Xu YS. The effect of sediment resuspension on phytoplanktonic communities [Dissertation]. Wuhan: Huazhong Agricultural University, 2007. [许炎生. 沉积物再悬浮对浮游植物群落结构的影响 [ 学位论文]. 武汉: 华中农业大学, 2007.]

[39] Wei HN. Relationship between algae and water nutrients and the decline of submerged plants [Dissertation]. Nanjing: Nanjing Normal University, 2013. [魏宏农. 附着藻类与水体营养盐及沉水植物衰亡的关系 [学位论文]. 南京: 南京 师范大学, 2013.]

[40] Dibble ED, Thomaz SM. A simple method to estimate spatial complexity in aquatic plants. Brazilian Archives of Biology and Technology, 2006, 49(3): 421-428.

[41] Taniguchi H, Nakano S, Tokeshi M. Influences of habitat complexity on the diversity and abundance of epiphytic invertebrates on plants. Freshwater Biology, 2010, 48(4) : 718-728.

[42] Rho J, Gunner HB. Microfloral response to aquatic weed decomposition. Water Research, 1978, 12(3) : 165-170.

[43] Warfe DM, Barmuta LA. Habitat structural complexity mediates food web dynamics in a freshwater macrophyte community. Oecologia, 2006, 150(1) : 141-154.

[44] Guibaud G, Bhatia D, D'Abzac P et al. Cd( II ) and $\mathrm{Pb}$ ( II ) sorption by extracellular polymeric substances ( EPS) extracted from anaerobic granular biofilms: Evidence of a pH sorption-edge. Journal of the Taiwan Institute of Chemical Engineers, 2012, 43(3): 444-449.

[45] Tian C, Si YB, Zhang YY. Sorption characteristic of $\mathrm{Pb}$ ( II ) and $\mathrm{Zn}$ ( II ) by biofilms in natural water. Journal of AgroEnvironment Science, 2011, 30(6): 1180-1184. [田超, 司友斌, 张圆圆. 自然水体生物膜对 $\mathrm{Pb}^{2+} 、 \mathrm{Zn}^{2+}$ 的吸附特性. 农业环境科学学报, 2011, 30(6): 1180-1184.] 